\title{
A ATUAÇÃO DO CONSELHO DO MERCADO COMUM NAS POLÍTICAS PÚBLICAS DE DIREITOS HUMANOS NO MERCOSUL
}

http://dx.doi.org/10.21527/2176-6622.2021.55.6-19

Recebido em: 22/2/2020

Modificações solicitadas em: 20/4/2020

Aceito em: 21/7/2020

Amanda Carolina Buttendorff Rodrigues Beckers

Autora correspondente. Universidade do Contestado - Campus Rio Negrinho. R. Pedro Simões de Oliveira, 315 Centro, 89295-000. Rio Negrinho/SC, Brasil. http://lattes.cnpq.br/1244275248377705. http://orcid.org/0000-0002-0116-6155. amandacbeckers@gmail.com

Luís Alexandre Carta Winter

Pontifícia Universidade Católica do Paraná. Curitiba/PR, Brasil.

\section{RESUMO}

O presente estudo visa à análise da atuação do Conselho do Mercado Comum - órgão máximo do Mercosul -, ao qual incumbe a condução política do processo de integração regional na consecução das políticas públicas em Direitos Humanos. Volta-se, na sequência, ao Instituto de Políticas Públicas em Direitos Humanos - IPPDH -, órgão auxiliar exclusivamente direcionado à temática e sua atuação na formação de atores sociais. Para tanto, o trabalho, que trata do viés político e social do Mercosul, perpassa fatores históricos, políticos, sociais, jurídicos e econômicos do bloco, mediante estudo dos institutos da integração regional e do direito ao desenvolvimento e sua relação com a salvaguarda dos Direitos Humanos. A pesquisa teve base dedutiva, sendo estudo qualitativo, construído interdisciplinarmente, visando a responder ao problema proposto, qual seja: identificar e analisar qual ou quais as medidas do Conselho do Mercado Comum no desenvolvimento do Mercosul no que se refere às políticas públicas em Direitos Humanos, levando em consideração os objetivos do bloco e seus diálogos com aspectos econômicos, políticos e sociais. Com a construção das seções, responde-se o questionamento levantado na hipótese, demonstrando-se, durante o desenvolvimento do texto, a atuação do CMC na consecução das políticas públicas em Direitos Humanos no Mercosul, para, nas considerações finais, debater-se sobre a referida atuação, seus limites e possibilidades.

Palavras-chave: Direitos humanos. Mercosul. Integração regional. Desenvolvimento. Participação social.

\section{THE ACTING OF THE COMMON MARKET COUNCIL ON PUBLIC HUMAN RIGHTS POLICIES IN MERCOSUR}

\section{ABSTRACT}

This study aims to analyze the performance of the Common Market Council - Mercosur's highest organ, which is responsible for the political conduct of the regional integration process, in the pursuit of public policies on Human Rights. It then follows the Institute of Public Policies on Human Rights - IPPDH, an auxiliary body exclusively focused on the theme and its role in the formation of social actors. To this end, the work, which deals with the political and social bias of Mercosur, permeates the bloc's historical, political, social, legal and economic factors, by studying the institutes of regional integration and the right to development and their relationship with the safeguarding of human rights. Humans. The research had a deductive basis, being a qualitative study, built interdisciplinarily, aiming to answer the proposed problem, namely: to identify and analyze which measures of the Common Market Council the development of Mercosur regarding public policies in Human Rights, leading The bloc's objectives and its dialogues with economic, political and social aspects should be taken into consideration. With the construction of the chapters, we answer the question raised in the hypothesis, demonstrating, during the development of the text, the CMC's performance in the pursuit of public policies on human rights in Mercosur, so that in the final considerations it is possible to debate about this action, its limits and possibilities.

Keywords: Human rights. Mercosur. Regional integration. Development. Social participation.

\section{SUMÁRIO}

1 Introdução. 2 Panorama social do Mercosul. 3 As decisões do CMC em matéria de direitos humanos. 4 O IPPDH. 5 Considerações finais. 6 Referências. 


\section{INTRODUÇÃO}

O abalo na conjuntura global, decorrente da Segunda Guerra Mundial, trouxe mudanças irreversíveis na temática da proteção aos Direitos Humanos. A crescente preocupação com a salvaguarda internacional dos Direitos Humanos remonta ao Pacto da Sociedade das Nações e firmemente à Declaração Universal dos Direitos Humanos de 1948, que trouxe verdadeira transformação no entendimento acerca da necessidade de proteção de tais direitos não somente pelos Estados, mas também pela comunidade internacional.

Paralelamente a tal fenômeno, na América Latina, no período Pós-Segunda Guerra, surge uma nova conjuntura regional, na qual os países do continente intentaram reformular seus processos econômicos a fim de fomentar a industrialização e o crescimento econômico.

Foi neste cenário de mudanças globais e regionais que, em 1991, firmou-se o Tratado de Assunção, instituidor do Mercosul. O referido documento formalizou a criação do bloco econômico sem, contudo, relegar à margem das preocupações dos Estados envolvidos o caráter humano e social, sem os quais não se pode, segundo seu preâmbulo, alcançar a integração regional e o esperado desenvolvimento econômico com justiça social, tampouco melhorar a condição de vida dos cidadãos dos Estados-membros como preconizava seu texto.

É justamente este enfoque, de um Mercosul político e não de sua faceta econômica, que este artigo aborda. Muitos foram os documentos posteriores e as disposições complementares ao Tratado de Assunção que delinearam o que hoje representa este bloco, o que se verá em momento oportuno.

O estudo volta-se à atuação do Conselho do Mercado Comum (CMC) na elaboração de políticas públicas em Direitos Humanos, o qual, mediante Decisão - nome dado às duas determinações -, criou órgão auxiliar exclusivamente voltado à temática: o Instituto de Políticas Públicas em Direitos Humanos - IPPDH. O referido órgão tem atuado principalmente na formação de agentes sociais e na educação em Direitos Humanos, ações sem as quais não se pode falar em instituição de políticas públicas mediante, principalmente, a Escola Internacional de Direitos Humanos do Mercosul.

A atuação do CMC via IPPDH tem se dado de forma horizontal, a fim de fomentar a discussão dos Direitos Humanos e as necessárias políticas públicas não somente entre os Estados, mas, principalmente, por meio daqueles que serão, ao mesmo tempo, atores e objeto de tais políticas - os nacionais dos referidos países.

Assim, diante da importância do Mercosul enquanto bloco econômico - e ainda da importância de um bloco econômico voltar-se ao eixo de proteção aos Direitos Humanos; das mudanças estruturais do bloco, com a movimentação política dos membros e a aproximação de países associados e observadores; e compreendendo que a integração regional só poderá ser alcançada mediante desenvolvimento social e respeito aos Direitos Humanos -, mostra-se de grande relevância o estudo da política de Direitos Humanos do bloco, bem como o estudo dos mecanismos instituídos nesta temática.

\section{PANORAMA SOCIAL DO MERCOSUL}

Ao longo dos anos o bloco ganhou visibilidade, fazendo crescer o interesse de outros países. Hoje é membro efetivo, além dos fundadores Argentina, Brasil, Paraguai e Uruguai, a Venezuela, que concluiu seu processo de adesão em 2012, mesmo ano em que se deu a assinatura do Protocolo de Adesão da Bolívia ao bloco, documento que deu início ao processo de adesão do país como Estado-parte (BRASIL, 2019).

O bloco contou ainda com os chamados Estados Associados, que, diferentemente dos membros efetivos, não adotaram a Tarifa Externa Comum - TEC. São eles Chile, Colômbia, Equador, Guiana e Suriname. Há ainda a figura dos "países observadores", que acompanharam as discussões e decisões do bloco, mas sem poder de participação de decisão. Atualmente são países observadores o México e a Nova Zelândia (BRASIL, 2019).

No intuito de concretizar o proposto, o bloco fixou objetivos específicos para a efetivação da integração regional, dentre os quais a criação de um programa de liberação comercial, que previa a introdução da livre-circulação de bens, serviços e fatores produtivos e o estabelecimento de uma Tarifa Externa Comum - TEC -, e a 
doutrina pontua dois objetivos principais: "aumentar a competitividade intrabloco, em face dos produtos externos (garante a margem de preferência nacional); preservar as conquistas já realizadas; e possibilitar maior unidade nas negociações comerciais com outros Estados e blocos regionais" (VARELLA, 2012, p. 461).

A determinação pela criação de um programa de liberação comercial foi executada com base em um cronograma, o qual, diante de querelas pontuais de execução, teve de ser adequado em algumas ocasiões. A maior parte dos produtos teve, até chegar à tarifa zero, ou seja, liberação total, uma redução gradativa das tarifas (VARELLA, 2012, p. 460).

A ideia inicial era a abrangência total de produtos. Ainda hoje, entretanto, há uma chamada lista de exceção, na qual figuram produtos sob os quais ainda existem as chamadas barreiras comerciais.

Com isto, embora almejasse em sua criação a formação de um mercado comum, o Mercosul é caracterizado, hoje, como uma união aduaneira em fase de consolidação, ou união aduaneira incompleta, como refere-se parte da doutrina. Isto porque ainda não há total superação das barreiras comerciais, posto que muitos produtos estão inseridos na chamada lista de exceção à TEC.

Sobre as características do mercado comum, leciona Winter (2008, p. 75):

O almejado enquadramento como mercado comum visava ir mais além. Inserido no conceito do modelo de associação "mercado comum", insere-se o propósito pelo atingimento das chamadas cinco liberdades, em tese defendida por Carta Winter. São elas: (i) livre circulação de bens, o que perpassa a necessidade da criação de uma política externa comum e pela implementação da TEC; (ii) livre prestação de serviços; (iii) livre circulação de pessoas; (iv) livre circulação de capitais; (v) liberdade concorrencial, que depende da igualdade de condições e regramentos econômicos, jurídicos, fiscais, políticos e sociais, a fim de submeter igualmente os produtores dos Estados-partes. Tal modelo é mais abrangente que a União Aduaneira, eis que prevê não somente a livre circulação de pessoas, mas também dos demais fatores produtivos, razão pela qual torna-se também mais árduo de alcançar, diante da necessidade de harmonização de diversos setores. A União Aduaneira, que visa a "eliminação das restrições comerciais tarifárias e extra-tarifárias, adoção de regras comuns para importação e exportação de produtos". Trata-se de uma área de livre-comércio - descrita no artigo XXIV, 8, "b" do GATT, como "um grupo de territórios aduaneiros entre os quais se eliminam os direitos de aduana e as demais regulamentações comerciais restritivas com respeito ao essencial dos intercâmbios comerciais dos produtos originários dos territorios constitutivos da dita zona de livre comércio" - acrescida do instituto da chamada tarifa externa comum, somada ainda de outras medidas que resultaram uma política comercial externa comum.

A referida lista de exceções inicialmente foi elaborada com um restrito número de produtos - e, em tese, deveria ser progressivamente revisada para excluir tais exceções e acaba por ser renovada sucessivamente, dificultando a exclusão total das exceções.

Veja-se que os mecanismos determinados no Tratado de Assunção para a instituição do sonhado mercado comum, visam, além do fomento econômico dos Estados-partes, a fomentar iguais oportunidades de crescimento aos países desenvolvidos, com base nos princípios da cooperação e reciprocidade constantes do Tratado. "O mercado comum deveria dar oportunidades iguais de aceleração do desenvolvimento a todo e qualquer país latino-americano" (CEPAL, 2017). Assim, haveria uma tendência a diminuir assimetrias econômicas e sociais dos membros. "Mas, como as situações relativas dessas nações são desiguais, em virtude de seus diferentes graus de evolução, impõe-se um tratamento diferenciado para conseguir, na medida do possível, essa igualdade de oportunidades em relação ao mercado comum" (BIELSCHOWSKY, 2017 . p. 350).

Embora não sejam o objeto do presente estudo, os aspectos econômicos não podem ser relegados à margem da análise, um dos objetivos do Mercosul, dada a importância dos números que o bloco representa na atualidade. Os Estados-parte do bloco "abrangem, aproximadamente, 72\% do território da América do Sul; $70 \%$ da população sul-americana e 77\% do PIB da América do Sul em 2012 (US\$ 3,18 trilhões de um total de US\$ US\$ 4,13 trilhões, segundo dados do Banco Mundial)" (BRASIL, 2019).

Não obstante a importância do fator econômico do bloco, e todas as adaptações havidas institucionalmente no Mercosul econômico, é relevante para o deslinde deste trabalho ressaltar as modificações havidas na estrutura do Mercosul político e no que diz respeito à integração regional e ao fator humano.

Nestas quase três décadas de existência foi necessário adequar a estrutura institucional do bloco. A fim de instrumentalizar os firmados compromissos, hoje o bloco conta com o Parlamento do Mercosul - Parlasul -, que, até 2020, deverá contar com eleições diretas para o preenchimento das vagas, calculadas de acordo 
com o "princípio da proporcionalidade atenuada: há um número mínimo de representantes por Estado Parte (18 por país) e uma escala de assentos adicionais a ser aplicado para cada Estado Parte em proporção à sua população" (PARLASUL, 2017).

Com sede em Montevidéu, criado em 2005, o Parlasul, "instituição de caráter permanente e de natureza consultiva, e, portanto, sem competência legislativa, mas com a finalidade de representar os interesses dos cidadãos" (GOMES, 2011, p. 49), tem como objetivo principal "emitir opiniões sobre os diferentes aspectos do processo de integração" (VARELLA, 2012, p. 464).

Seu protocolo instituidor expressa o compromisso com a consolidação da democracia e dos Direitos Humanos no âmbito do Mercosul, trazendo, ainda, a possibilidade de interação entre a instituição e os cidadãos dos Estados-partes, principais interessados na efetivação de tais direitos. "Referido distanciamento, entre as instituições do bloco econômico e os interesses dos cidadãos, pode ser suprido com a atuação, cada vez maior, do Parlamento do Mercosul, de forma a legitimar a adoção das referidas políticas, tornando-se um foro, ainda que político, para a inclusão, debate e efetivação de outras políticas, como a democracia, proteção aos direitos humanos, redução das diferenças sociais e realização de investimentos estruturais nos países" (GOMES, 2011, p. 50).

Cabe ao Parlamento preservar o regime democrático nos Estados-Partes; elaborar e publicar anualmente um relatório sobre a situação dos Direitos Humanos nos Estados-Partes; requerer informações aos demais órgãos no que se refere às questões do processo de integração; convocar, via CMC, os representantes dos demais órgãos para avaliar e trocar informações sobre o processo de integração, dentre outras funções.

A criação de um órgão de participação social e muitas outras políticas na área dos Direitos Humanos, que serão analisadas no último tópico deste trabalho, reforça a ideia de que, ainda que em sua origem, o Mercosul tenha finalidade econômica, e hoje se pauta também pela necessidade de redução das desigualdades sociais e não somente comerciais e econômicas, premente à necessidade de investimentos estruturais nos Estados-partes, a fim de se alcançar o sucesso da almejada integração (GOMES, 2011, p. 58).

O objetivo da integração regional só poderá ser alcançado com o compromisso dos Estados-partes em "conjugar esforços na adoção de políticas conjuntas e que tenham por finalidade valorizar os Direitos Humanos, direitos sociais e a democracia" (GOMES, 2011, p. 59), posto que democracia e Direitos Humanos são valores essenciais para qualquer processo de integração.

Neste contexto, em 1998 o Protocolo de Ushuaia "firmou um pacto pela democracia no âmbito do Mercosul, no sentido de que a manutenção das instituições democráticas seria condição indispensável para existência e desenvolvimento do bloco" (MORAES, 2017, p. 1). Dentre várias disposições importantes, o documento previu punições para os Estados que estivessem sob ameaça ou tivessem sua ordem democrática rompida, dentre as quais destaca-se o previsto no artigo 5: "a suspensão do direito de participar nos diferentes órgãos dos respectivos processos de integração até a suspensão dos direitos e obrigações resultantes destes processOs" (MERCOSUL, 2020).

O referido documento ganhou destaque no cenário internacional por ocasião da suspensão do Paraguai em decorrência do impeachment do então presidente Fernando Lugo. A forma de sua saída da chefia de governo do país foi considera pelos demais Estados-partes "nítida ofensa ao devido processo legal e ao direito de ampla defesa, traduzindo-se, portanto, em medida arbitrária, não condizente com os princípios do Estado Democrático de Direito" (MORAES, 2017, p. 12), razão pela qual foi tomada a decisão de suspensão do Estado no bloco.

Tal suspensão, ocasionada pela quebra da cláusula democrática preconizada no Protocolo de Ushuaia, acabou por contribuir para a aprovação do ingresso da Venezuela como membro efetivo do bloco, o que não era anuído pelo Paraguai, que não pode se opor no momento justamente em razão da suspensão.

Controversa desde o início, a participação da Venezuela como membro efetivo do Mercosul voltou ao noticiário internacional em dezembro de 2016, quando o país foi suspenso por não ter cumprido a pauta comercial acordada como requisito para sua admissão no bloco. Não obstante, curiosamente, em abril de 2017, os Estados-partes convocaram uma reunião de emergência na qual a chancelaria presente leu um comunicado oficial requerendo que o país respeitasse a separação de poderes e a ordem democrática, consignando o início da aplicação da cláusula democrática ao país, que vive uma crise política (EL PAís, 2017). 
Paralelamente a tais questões de reafirmação da ordem democrática nos Estados-partes, em 2004 adveio o Protocolo de Olivos, que instituiu o atual sistema de solução de controvérsias do Mercosul, instaurando o Tribunal Permanente de Revisão - TPR. Anteriormente, o sistema era baseado no Protocolo de Brasília de 1991 e no Protocolo de Ouro Preto de 1994, e, após o início dos procedimentos arbitrais, foi verificada a "necessidade de instituição de uma nova sistemática visando a necessidade de garantir a correta interpretação, aplicação e cumprimento dos instrumentos fundamentais do processo de integração" (MARTINS, 2006, p. 80).

Verifica-se, pois, que foram várias as mudanças institucionais do Mercosul ao longo dos anos. Há que se considerar o foco ao setor político e social do bloco, dentre os quais se destaca a salvaguarda aos Direitos Humanos, ora objeto de estudo, conforme se verá adiante.

\section{AS DECISÕES DO CMC EM MATÉRIA DE DIREITOS HUMANOS}

O Conselho do Mercado Comum, órgão político máximo do Mercosul, tem, ao longo da história do bloco, intensificado sua atuação na temática dos Direitos Humanos mediante suas decisões, e as mais relevantes e transversais ao tema serão ora abordadas.

Em 1991 a Decisão 07/1991 explicitou sua preocupação com a educação enquanto Direito Humano fundamental e fator essencial para o fortalecimento do processo de integração. Consignou uma vez mais sua intenção em fomentar o bem-estar e a justiça social na região, propondo um grupo de trabalho formado pelos ministros da Educação dos Estados-partes.

Em 1992, por meio da Decisão 07/1992, reafirmando a premissa de que a educação enquanto Direito Humano fundamental é de igual forma importante para o processo integrador, o bloco instituiu o Plano Trienal de Educação, cujos objetivos eram (i) a formação de consciência cidadã como mecanismo de integração; (ii) a capacitação de recursos humanos para promover estratégias de desenvolvimento na área da educação; e (iii) a compatibilização e harmonização dos projetos educacionais dos envolvidos. Isso demonstra a positivação de uma política voltada à área já considerada estratégica em Decisão anterior, o que sinaliza a transformação em política pública por meio da criação do Plano Trienal - o Direito Humano à educação reconhecido no documento citado anteriormente.

A Decisão 001/1995 confirmou a manutenção das reuniões ministeriais nas áreas temáticas consideradas estratégicas, sem prejuízo de criação de outras. O referido documento, embora não crie efetivamente inovação na área e não se trate propriamente de política instituída, é importante por reafirmar a preocupação com as temáticas transversais estratégicas em Direitos Humanos, confirmando-o como um dos temas prioritários no bloco.

A Decisão 003/1995 criou a reunião de ministros da Saúde, com o intuito de propor políticas na área da saúde, entendendo o documento ser conveniente à integração regional. A coordenação de políticas conjuntas na área, a fim de efetivar o disposto no Tratado de Assunção, preconiza o desenvolvimento humano e a justiça social dos membros.

Em 1995 o CMC decidiu pela criação da Reunião de Ministros da Cultura, com vistas a promover a difusão de conhecimentos da cultura e valores tradicionais dos Estados-partes, cabendo às autoridades reunidas propor políticas de cooperação na área da cultura.

A Decisão 09/1996 firmou o Protocolo de Integração Educacional para a formação de recursos humanos no nível de Pós-Graduação entre os países membros do Mercosul. O documento tem como fundamento o importante papel da educação no processo da integração regional, tendo como base a cooperação entre os Estados e suas instituições de ensino, com o objetivo de promover o desenvolvimento harmônico da região, principalmente no que se refere à formação de recursos humanos em âmbito de Pós-Graduação.

Para instrumentalizar tal propósito, o documento prevê uma série de objetivos a serem trabalhados pelos órgãos responsáveis pela Pós-Graduação em cada país membro (ROSEVICS, 2015, p. 120) - no Brasil a Capes, como o estabelecimento de critérios comuns de avaliação no nível de Pós-Graduação; a criação de um sistema de intercâmbio de docentes e discentes; a cooperação entre pesquisadores; a instituição de cursos em áreas estratégicas; sem prejuízo de outras. 
Mediante a Decisão 11/1996 adveio o Protocolo de Integração Cultural do Mercosul, no qual os Estados-partes, movidos pelo respeito à diversidade de identidades e cientes de que a difusão cultural é elemento importante no processo de integração, comprometem-se a promover projetos culturais conjuntos. Seus artigos preveem a criação de iniciativas nas áreas artísticas, de pesquisa, de televisão, de cinema, de bibliotecas, de museus, entre outras, buscando abranger as mais diversas formas de manifestação cultural.

A Decisão 19/1997 institui o Acordo Multilateral de Seguridade Social do Mercosul, que reconheceu o direito à seguridade social aos trabalhadores - e seus familiares - que tenham prestado serviços em quaisquer dos Estados-Partes, sendo ou não nacionais destes. O documento prevê que sua aplicação se dará de acordo com a legislação e consequentes prestações pecuniárias e de políticas de assistência de cada país.

A Decisão 22/1997 instituiu o Protocolo de Intenções entre o Mercosul e a ONU para a educação, a ciência e a cultura. Mercosul e Unesco, no intuito de promover o desenvolvimento regional, firmaram o documento a fim de elaborar projetos de cooperação nas áreas citadas, a fim de fomentar a integração regional.

Mediante a Decisão 25/1997, o CMC prorrogou a vigência do Plano Trienal para o setor de educação, por considerar a área estratégica para a consecução do processo integrador.

A Decisão 13/1998 efetivou novo Plano Trienal de Metas para o Setor Educacional, com abrangência de 1998 a 2000. O referido documento veio solidificar o disposto nas decisões 07/1991 e 07/1992, reiterando a importância da educação para a integração regional e melhoria na qualidade de vida dos nacionais dos Estados-partes, pautado pelo respeito à diversidade, à autodeterminação, ao compromisso democrático e à educação de qualidade.

O documento traz ainda resultados dos sete anos de existência do chamado setor educativo do bloco, que, segundo o documento, conseguiu importantes êxitos na área, dentre os quais se destacam: (i) a aprovação de protocolos facilitadores do reconhecimento de certificações e consequente livre-circulação de estudantes; (ii) início dos trabalhos de adequação dos currículo educacionais e de incentivo de aprendizagem às línguas dos países e suas peculiaridades em história e geografia; (iii) aprovação de protocolos facilitadores para o intercâmbio de discentes e docentes; e (iv) criação de um sistema de comunicação no setor educacional do Mercosul.

Veja-se a importância de referido documento, que elencou os avanços obtidos no setor educacional, sendo possível, assim, visualizar mais claramente os resultados conquistados no que diz respeito à educação, com medidas relevante de intercâmbio de conhecimento e reconhecimento da relevância dos aspectos regionais, geográfico, históricos e culturais dos povos no ensino regular.

A Decisão 61/2000, que prevê a criação da Reunião de Ministros e Autoridades de Desenvolvimento Social do Mercosul, já determinada na Carta de Buenos Aires, resultado da XVIII Reunião do Conselho do Mercado Comum, instituiu o Foro de Consulta Política do Mercosul, que, conjuntamente com a Reunião dos Ministros, deve propor medidas com o fito de fomentar o desenvolvimento social dos Estados-Partes.

A Decisão 15/2001 criou um grupo de trabalho chamado Setor Educacional do Mercosul - SEM -, responsável "pela condução dos estudos e das viabilidades dos acordos a serem propostos para a área educacional do bloco" (ROSEVICS, 2015, p. 118), tendo criado, ainda, o primeiro plano de trabalho da área.

Novamente o direito à educação foi objeto do CMC mediante a Decisão 26/2002, que aprovou acordos de cooperação firmados na XXIII Reunião dos Ministros da Educação do Mercosul, da Bolívia e Chile, firmando documentos no intuito de uniformizar o reconhecimento de certificados e fomentar os recursos humanos mediante programas de Pós-Graduação com os países citados.

A Decisão 24/2004 criou o Centro Mercosul de Promoção ao Estado de Direito. O documento parte da premissa de que o Estado de Direito tem como base a democracia e a eficácia das instituições, sendo, ainda, essencial para este a proteção aos Direitos Humanos, as liberdades e o desenvolvimento dos países envolvidos. Com esta finalidade, o Centro criado visa à pesquisa nas temáticas correlatas e à criação de políticas de capacitação e difusão dos recursos humanos. A determinação era de que as atividades fossem desenvolvidas na sede do Tribunal Permanente de Revisão em Assunção. A proposta compreendia a realização de conferências e seminários, cursos de capacitação, programas de intercâmbio e a manutenção de um sítio na internet e de uma biblioteca própria. 
A Decisão 37/2004 instituiu projetos de acordos de cooperação contra o tráfico de pessoas entre o bloco, Chile e Bolívia, visando à edição de medidas para mapear, prevenir e combater o problema. $O$ referido documento demonstra a sinergia do CMC com problemáticas relevantes a atuais ao bloco, como o enfrentamento do tráfico de pessoas.

Os Estados-partes já haviam assinado e ratificado o Protocolo Adicional à Convenção da ONU contra o Crime Organizado Transnacional relativo à Prevenção, Repressão e Punição do Tráfico de Pessoas, o chamado Protocolo de Palermo (SOARES, 2011, p. 188), tendo se comprometido não só internamente em realizar ações contra o fato, mas agido também em âmbito regional.

A Decisão 40/2004 instituiu a Reunião de Altas Autoridades sobre Direitos Humanos do Mercosul RAADH. A criação de órgão específico à temática levou em consideração a necessidade de um núcleo de atenção aos Direitos Humanos, considerados fundamentais para a consecução de sociedades livres nos países membros e na busca do desenvolvimento econômico e social.

Nesta mesma linha, o estudo de Ignacy Sachs atrela o desenvolvimento aos Direitos Humanos em um processo de luta. Para ele "a ascensão dos direitos é fruto de lutas, que os direitos são conquistados, em um processo histórico cheio de vicissitudes, por meio do qual as necessidades e as aspirações se articulam em reivindicações e em estandartes de luta, antes de serem reconhecidos como direitos" (SACHS, 1998, p. 156).

Verificou-se, neste cenário, a necessidade de que os Estados não mais agissem isoladamente nesta temática, mas criassem mecanismos de ação conjunta. "O Estado se acha integrado na comunidade internacional, e é missão nacional de cada povo que decide sua posição de equilíbrio na ordem da humanidade" (MEIRELLES, 1991, p. 48).

Trata-se de um grande avanço na temática de proteção aos Direitos Humanos, que, agora, além de serem abordados por políticas transversais nos mais diversos setores do bloco, passaram a contar com um órgão espeficicamente voltado ao assunto, o que demonstra o destaque que a temática - já presente no Tratado de Assunção - veio adquirindo no bloco ao longo dos anos.

Em 2005, Bolívia, Chile, Colômbia e Venezuela, países observadores, fimaram compromissos de salvaguarda ao Compromisso Democrático do Mercosul, por meio das decisões 14/2005, 15/2005 e 16/2005.

Da Decisão 17/2005 adveio o Protocolo de Assunção sobre compromisso com a promoção e proteção dos Direitos Humanos no Mercosul, reconhecendo expressamente que a proteção efetiva aos Direitos Humanos é indispensável para a consolidação do processo de integração regional.

O Protocolo reafirmou os compromissos firmados em documentos anteriores, como o Protocolo de Ushuaia, o Compromisso Democrático do Mercosul e a própria Carta Democrática Interamericana, consignando que o respeito aos Direitos Humanos é fundamental à democracia, a qual deve ser protegida e promovida mediante cooperação dos Estados-partes, que, nos termos do protocolo, se compromete a verificar casos de violação de direitos havidos em seus territórios.

Este novo instrumento, ratificado por todos os membros, envolve uma mudança qualitativa importante no Mercosul, porque os Direitos Humanos estão entrincheirados como um fator chave no processo de integração. São destacados os princípios comuns, a vocação dialógica com o sistema universal e o interamericano, assim como o dever fundamental de proteger, promover e garantir os Direitos Humanos como uma conditio para a consolidação do bloco (ANTONIAZZI, 2017, p. 12).

A Decisão 19/2006 encomendou à Comissão Permanente de Representantes do Mercosul que elaborasse um projeto de Instituto Social do Mercosul, que trabalhasse conjuntamente com a Secretaria Permanente Social a fim de traçar diretrizes para atuação na área citada, o que se concretizou, conforme será visto mais adiante, na Decisão respectiva, sendo hoje órgão auxiliar de grande relevância na consecução de políticas públicas sociais.

A Decisão 24/2006 encomendou a criação de um projeto para um Observatório da Democracia no Mercosul, considerando que é dever do bloco fomentar projetos de desenvolvimento humano, democrático e social nos Estados-partes. 
Mediante a Decisão 34/2006 o bloco elaborou diretrizes para a elaboração de um plano de diminuição das assimetrias dos partícipes, principalmente no que se refere ao Paraguai e Uruguai, cuja situação de pontuais diferenças já tinha sido apontada no Tratado de Assunção. Tal plano englobaria traçar objetivos de curto, médio e longo prazos na temática, criar instrumentos de política comunitária e criar ações para fomentar as economias locais.

A Decisão 03/2007 previu a criação do Instituto Social do Mercosul, que visava a fomentar a dimensão social e o desenvolvimento do bloco, superar as assimetrias, sistematizar indicadores sociais e promover o intercâmbio de boas práticas sociais. Atualmente, o ISM tornou-se verdadeira ferramenta de fortalecimento institucional, sendo organimo técnico de apoio bastante atuante nas ações sociais promovidas pelos Estados, dentre as quais a elaboração de cursos de formação de agentes na temática (STF, 2017).

A Decisão 05/2007 instituiu o Observatório da Democracia do Mercosul, que, dentre os principais objetivos, tinha o fortalecimento das instituições democráticas e do disposto no Protocolo de Ushuaia. O Observatório reuniria agentes dos Estados-partes, os quais seriam responsáveis pela nomeação de observadores para trabalhar no projeto, que visa à difusão e efetivação do disposto no Protocolo de Ushuaia, o fortalecimento de seus objetivos e o acompanhamento dos processos eleitorais nos Estados-partes (RIBEIRO, 2017, p. 184).

O Acordo entre Estados-partes do Mercosul e Estados Associados sobre cooperação regional para a proteção dos direitos das crianças e adolescentes em situações de vulnerabilidade, foi instituído por meio da Decisão 25/2008 e, posteriormente, instrumentalizado pela aprovação da criação da base de dados sobre a criança e o adolescente em situação de vulnerabilidade, estabelecida pela Decisão 26/2008.

A Decisão 37/2008 deliberou sobre a estrutura institucional do ISM, trazendo observações gerais administrativas e fiscais sobre o órgão. A preocupação social do Mercosul levou o bloco a elaborar a Decisão 39/2008, que instituiu uma Comissão de Ministros de Assuntos Sociais, criado como um órgão auxiliar ao $\mathrm{CMC}$, visando a trabalhar especificamente na temática e criar planos de ação na área.

A Decisão 14/2009 criou o Instituto de Políticas Públicas e Direitos Humanos - IPPDH - com o fito de fomentar a elaboração de políticas públicas voltadas à temática, compreendendo que a efetivação dos Direitos Humanos são fundamentais para o desenvolvimento do bloco.

A Decisão 12/2010 previu a estrutura organizacional o Instituto de Políticas Públicas e Direitos Humanos, tendo sido aprovado seu orçamento pela Decisão 13/2010. O IPPDH, frise-se, será objeto de estudo do próximo item.

A participação social foi tema da Decisão 65/2010 que criou a unidade de apoio à participação social, promovendo a coordenação de políticas públicas na área, tendo sido complementada pela Decisão 67/2010, que originou o Plano Estratégico de Ação Social do Mercosul, o qual foi complementado pela Decisão 12/2011, que estabeleceu novas metas ao Plano.

A Decisão 27/2011 aprovou o Protocolo de Montevidéu sobre o compromisso com a Democracia no Mercosul, que veio reiterar o já disposto no documento anterior e estabelecer parâmetros de atuação e sanções por ocasião de possíveis violações.

Com a Decisão 14/2012 instituiu-se a Diretriz para a Política de Igualdade de Gênero, que visava a estabelecer uma política especialmente voltada para esta temática, haja vista a importância da criação de ações afirmativas no setor.

A Decisão 44/2012 criou o fundo para convergência estrutural do projeto "Construindo uma infraestrutura em Direitos Humanos", que visava a fomentar a captação e gerenciamento estratégico de recursos na temática dos Direitos Humanos, fortalecento a atuação do IPPDH, a participação social e a formação de atores regionais para atuarem neste seguimento.

A Decisão 07/2015 traçou diretrizes para a Política de Bons Tratos à criança e ao adolescente, objetivando a prevenção da violência enquanto mecanimo de consolidação dos Direitos Humanos da infância e juventude e preconizando o crescimento seguro e em ambiente sadio, com acesso à educação, saúde, alimentação adequada e outros. 
A Decisão 08/2015 institui diretrizes para a criação de uma Política de Educação e Cultura em Direitos Humanos, com o fito de fortalecer a educação em Direitos Humanos no âmbito regional, promovendo a cidadania, a cultura de paz e o respeito à democracia.

A Decisão 09/2015 organizou a Reunião de Ministros e Autoridades sobre o Direitos dos Afrodescentendes, considerando a importância da diversidade de formação histórica e populacional dos Estados-partes do bloco.

O Fundo para a convergência estrutural do Projeto "Mercosul social” foi instituído pela Decisão 37/2015. O projeto trouxe a previsão de custos e origem do fomento, perpassando as disposições do Fundo para a Convergência Estrutural do Mercosul (Focem), esclarecendo, ainda, as principais áreas estratégicas de investimento.

Verifica-se, pois, que o CMC tem, ao longo dos anos, emitido Decisões nos mais variados temas atinentes à salvaguarda dos Direitos Humanos no bloco. A criação da RAADH e, posteriomente, do IPPDH demonstram a importância que a temática tem para a consecução do desenvolvimento e da integração regional, conforme se verá adiante.

\section{O IPPDH}

A salvaguarda aos Direitos Humanos é premissa basilar para um Estado comprometido com o desenvolvimento de seus cidadãos. "A teoria crítica dos Direitos Humanos propõe um diálogo intercultural como mecanismo de interação entre as diferentes culturas. Uma inter-relação pautada pelo reconhecimento e respeito à diferença" (SOUZA JÚNIOR; ESCRIVÃO FILHO, 2016, p. 34).

No âmbito do Mercosul, "uma constatação que se impõe reside no reconhecimento do alto grau de heterogeneidade dos países que integram o Mercosul, tanto do ponto de vista do seu crescimento econômico recente quanto das condições de vida de sua população" (PITANGUY; HERINGER, 2017, p. 12).

A preocupação com a salvaguarda os Direitos Humanos, que já era recorrente nas decisões do CMC, conforme verificado no item anterior, consolidou-se com a Decisão 40/04, que deu origem à Reunião das Altas Autoridades sobre Direitos Humanos do Mercosul - RAADH.

Verifica-se que a Decisão prevê uma "atuação conjunta com os órgãos competentes na matéria dos Estados-Partes e Associados, visando à pesquisa, capacitação e assessoramento técnico na construção de políticas públicas voltadas à temática dos Direitos Humanos, sendo o responsável pelo direcionamento estratégico das ações da temática no bloco" (WINTER; BECKERS, 2016, p. 11).

Confirmou-se, no ano seguinte, quando os países membros assinaram o chamado Protocolo de Assunção sobre o Compromisso com a Promoção e a Proteção dos Direitos Humanos do Mercosul, reafirmando os princípios e normas contidos na Declaração Americana de Direitos e deveres do Homem, na Convenção Americana sobre Direitos Humanos e outros instrumentos regionais de Direitos Humanos, assim como na Carta Democrática Interamericana e ressaltando o expressado na Declaração e no Programa de Ação da Conferência Mundial de Direitos Humanos de 1993, que a democracia, o desenvolvimento e o respeito aos Direitos Humanos e liberdades fundamentais são conceitos interdependentes que se reforçam mutuamente.

"O respeito e a promoção dos Direitos Humanos constituem condições indispensáveis para a integração" (IPPDH, 2016). O bloco tem compreendido o tema como de central importância, considerando sua estreita relação com a democracia dos Estados-partes. Neste sentido, "os Direitos Humanos não são pensados apenas como um limite para a opressão e para o autoritarismo, mas também como um guia para o desenvolvimento de políticas públicas e o fortalecimento das instituições democráticas" (IPPDH, 2016).

Neste contexto, verifica-se uma verdadeira modificação na concepção do papel dos Estados, que não mais devem somente respeitar os Direitos Humanos, mas, sim, promover ações para concretizá-los. "Ao mesmo tempo, impacta na concepção dos Direitos Humanos, como campo específico de política pública e como um enfoque a ser incorporado em políticas governamentais" (IPPDH, 2016).

Rui Duguit (2009, p.75) já apontava para uma modificação na função do Estado, esposando sua tese de uma nova concepção, pautada pela realidade social e voltada para a natureza sociológica do fenômeno jurídico, diminuindo a distância imposta ao direito, por parte da doutrina, para com as demais ciências sociais. 
Essas mudanças têm envolvido uma adequação na concepção do papel dos Estados, que não só devem respeitar os Direitos Humanos, mas também para promover medidas eficazes para garantir suas ações de exercício. Por sua vez, eles têm impactado o conceito de direitos humanos como um campo específico de política pública e como uma abordagem para incorporar nos campos que definem as políticas do governo (PATRINÓs, 2014. p. 114).

É neste cenário, "voltado à função de existir, que se vislumbra a necessidade da integração regional entre os Estados e implementação de políticas públicas em Direitos Humanos" (WINTER; BECKERS, 2016, p. 2).

Neste contexto, o Mercosul consolida sua dimensão social e política apoiando os governos na implementação de estratégias nacionais em direitos humanos, favorecendo a coordenação entre as políticas dos diferentes Estados e incentivando estratégias regionais para avançar nos direitos e na cidadania. Ao mesmo tempo, favorece a participação social de alcance regional sobre temáticas fundamentais para o aprofundamento das democracias na região (IPPDH, 2016).

Diante de tal quadro, visando à integração regional, e preocupado com o desenvolvimento e a qualidade de vida dos cidadãos dos Estados-partes, e ciente das diferenças de realidade social entre os membros, o bloco tem atuado na temática, como já visto, mediante as decisões do Conselho do Mercado Comum. "O aprofundamento das relações dentro do bloco levará os países-membros a buscarem soluções em conjunto e equalização de dispositivos jurídicos internos (além de acordos entre si) para dar continuidade ao processo de integração" (PITANGUY; HERINGER, 2017, p. 19).

O Mercosul consolida sua dimensão social e política apoiando os governos na implementação de estratégias nacionais em direitos humanos, favorecendo a coordenação entre as políticas dos diferentes Estados e incentivando estratégias regionais para avançar nos direitos e na cidadania. Ao mesmo tempo, favorece a participação social de alcance regional sobre temáticas fundamentais para o aprofundamento das democracias na região (IPPDH, 2016).

No âmbito da RAADH, adveio a proposta de criação de um organismo regional de direitos humanos, cujos trabalhos seriam baseados na identidade e no desenvolvimento dos países do bloco, concretizada mediante a já abordada Decisão 14/09 do CMC, que instituiu o Instituto de Políticas Públicas e Direitos Humanos do Mercosul.

O IPPDH tem por objetivo contribuir aos processos de planejamento, implementação e consolidação das políticas públicas em direitos humanos como marca central da identidade, do desenvolvimento e da integração dos países do Mercosul. Tem como funções principais a cooperação técnica, a pesquisa, a capacitação e o apoio à coordenação de políticas regionais de direitos humanos (IPPDH, 2016).

A criação de um órgão especializado voltado à temática, visou, sobretudo, a incentivar o fortalecimento da proteção dos referidos direitos intramuros, "mediante a concretização de políticas públicas em direitos humanos, que permitam a efetiva e eficaz implementação dos direitos humanos como eixo fundamental da identidade e do desenvolvimento do Mercosul" (RIBEIRO, 2011, p. 305).

Veja-se que a preocupação do bloco com o tema não fica no campo teórico, uma vez que o objetivo é instituir políticas públicas que efetivem os direitos positivados. Tão controverso quanto o conceito de Direitos Humanos, o conceito de política pública, ora utilizado neste trabalho, é de que o termo não se limita apenas à norma ou à busca pela efetividade da norma, mas a um complexo de normas e decisões do Poder Público que visa a efetividade do disposto na lei (KROLING; MARTINS, 2006, p. 154).

Com este fito, foi criado o Instituto de Políticas Públicas em Direitos Humanos do Mercosul (IPPDH), órgão que atua em diversas frentes de direitos, conforme necessidade específica detectada.

A Reunião de Altas Autoridades em Direitos Humanos e Chancelarias do Mercosul e Estados Associados - RAADH - e 114 do Instituto de Políticas Públicas de Direitos Humanos - IPPDH são configurações institucionais do Mercosul contribuir para a formação de uma comunidade política com o compromisso de respeitar e promoção de Direitos Humanos, enquanto eixo fundamental da identidade e desenvolvimento da região (Mercosul/CMC/DEC. N $N^{\circ}$ 26/03, $N^{\circ} 40 / 04$ YN 17/05) (tradução nossa) (PATRINÓS, 2014, p. 114). 
Trata-se de um conjunto de países em desenvolvimento, dos quais surge a necessidade de políticas públicas em proposta ao desenvolvimento aos Direitos Humanos e ao desenvolvimento social. Dentre as ações necessárias pode-se pontuar, com destaque, a transferência de renda, a promoção da cidadania, a prestação social e a formação sobre garantias e direitos (COELHO; TAPAJÓS; RODRIGUES, 2010, p. 20).

Considerando-se as diferenças sociopolíticas entre os países do bloco, é mais do que necessária a criação de uma diretriz que possibilite a formação intercultural e interdisciplinar sobre o assunto, pois "os direitos se constroem e desconstroem na medida dos contextos de desenvolvimento político e social de cada sociedade, em sua própria história" (SOUZA JÚNIOR; ESCRIVÃO FILHO, 2016, p. 38).

O desenvolvimento de uma educação intercultural na perspectiva apresentada é uma questão complexa, atravessada por tensões e desafios. Exige problematizar diferentes elementos do modo como hoje, em geral, concebemos nossas práticas educativas e sociais. As relações entre Direitos Humanos, diferenças culturais e educação colocam-nos no horizonte da afirmação da dignidade humana num mundo que parece não ter mais essa convicção como referência radical. Nesse sentido, trata-se de afirmar uma perspectiva alternativa e contra-hegemônica de construção social, política e educacional (tradução nossa) (CANDAU, 2008, p. 52).

Com este propósito, o Instituto de Políticas Públicas em Direitos Humanos do Mercosul (IPPDH) atua em diversas frentes de direitos, conforme necessidade específica detectada.

O Instituto cria ainda comissões específicas em temáticas estratégicas, de acordo com a demanda social, tais como: comissão da pessoa com deficiência; comissão de combate à discriminação, racismo e xenofobia; comissão de gênero; comissão do idoso; comissão LGBT e outras, visando a fomentar a discussão e a formação de políticas em áreas estratégicas.

O IPPDH produz pesquisa aplicada na área, realizando estudos de necessidade e viabilidade sobre a criação de políticas específicas em determinadas regiões. Desenvolve, ainda, ações de capacitação voltadas aos atores estatais, por meio da Escola Internacional de Política Pública em Direitos Humanos, que presta assistência técnica na área e proporciona cursos voltados à temática, tendo como público-alvo atores sociais e funcionários de instituições dos Estados-membros.

Como eixo de ação transversal aos temas de política acima mencionados e como fator fundamental para o desenvolvimento de políticas públicas de direitos humanos, o IPPDH apóia o fortalecimento de uma instituição pública de direitos humanos em nível nacional e regional. São iniciativas de capacitação de servidores públicos, geração de sistemas de informação técnica úteis para a gestão pública, bem como elaboração de diagnósticos, avaliações e apoio ao planejamento de políticas de direitos humanos (PATRINÓS, 2014, p. 115).

Entre as principais atividades desenvolvidas pelo IPPDH estão as palestras e debates na área, proporcionando intenso diálogo sobre a temática das políticas públicas de Direitos Humanos entre Estados e membros da sociedade civil. "A luta contra a exclusão deve ser abordada por meio de formas de se fazer que habilitem e capacitem as pessoas. As políticas públicas devem buscar incorporar instrumentos de participação e de fortalecimento do capital humano" (COELHO; TAPAJÓS; RODRIGUES, 2010, p. 117).

Mediante cooperação técnica internacional, o Instituto oferece apoio nos processos de formulação, execução e avaliação de políticas públicas nacionais para as autoridades e instituições de Direitos Humanos dos Estados-Partes e Associados do Mercosul.

O IPPDH traça suas diretrizes de trabalho mediante planos de ação anuais, prestando contas semestralmente das atividades desenvolvidas.

No Plano de Ação definimos nossa missão que é fortalecer os direitos humanos como um eixo fundamental da identidade e integração regional por meio da cooperação e coordenação de políticas públicas. Nossa visão é ser uma referência de organismos regional de ações estratégicas em políticas públicas em Direitos Humanos (IPPDH, 2016).

O objetivo da iniciativa de consulta aos Estados-membros é articular sociedade civil e atores estatais, promovendo integração entre as organizações dos Estados, visando à consolidação do debate sobre a temática no âmbito regional. 


\section{CONSIDERAÇÕES FINAIS}

Ao longo destas décadas foram muitas as mudanças no Mercosul econômico, rotineiramente objeto de estudos acadêmicos e digressões interessantes sobre o futuro do bloco enquanto união aduaneira, e sua permanente intenção de conformação em mercado comum. Pouco se viu entretanto como como objeto de pesquisa seu viés humano e social.

É difícil ponderar a que se deve tal fato, uma vez que, como visto ao longo do presente trabalho, desde o preâmbulo do Tratado de Assunção, seu documento instituidor, já se vislumbrava a preocupação com a dignidade e qualidade de vida dos cidadãos dos Estados-partes e a justiça social. Como falar em melhoria da dignidade, qualidade de vida e justiça social sem voltar as atenções à temática dos Direitos Humanos? Indo além, como falar em desenvolvimento e integração regional sem atentar à salvaguarda dos Direitos Humanos?

Com o presente trabalho entendeu-se que não é factível tal possibilidade. Mediante o estudo da estrutura do bloco, a evolução histórica dos processos de integração regional e a atual conjuntura dos Estados-partes, não raras vezes acometidos por questões sociais, humanas e democráticas, restou confirmada a hipótese de que não há integração regional no bloco, e desenvolvimento - nos termos utilizados na construção teórica desta pesquisa -, sem proteção aos Direitos Humanos.

Ainda que assim não fosse, e não compreendida como crucial a proteção aos Direitos Humanos, como relegar à margem a questão da salvaguarda aos Direitos Humanos em países de grande assimetria social e com "democracias" tão jovens?

A preocupação com temas que não o foco principal do bloco, demonstra a importância que os Direitos Humanos tinham mesmo no princípio das atividades. As questões de difusão de conhecimento e da atuação em educação e formação de agentes, temática da primeira Decisão alinhada ao eixo humano, sempre figurou entre as ações mais recorrentes do CMC, o que demonstra a preocupação, presente desde os idos de 1991, com a difusão de conhecimento e educação em Direitos Humanos como premissa basilar para fomentar o estabelecimento de outros temas transversais.

Certamente ainda há muito a ser feito, principalmente no que diz respeito à divulgação de tais políticas, à formação de agentes e à participação social, posto que para que haja intensa participação é necessário que os grupos de interesse, movimentos sociais e atores da sociedade civil tenham conhecimento de tais ações e possam usufruir de tal política, absorvendo conhecimento institucional, dialogando com agentes de outros países, compreendendo de que forma dar mais visibilidade às suas causas e assim promover a salvaguarda dos Direitos Humanos.

\section{REFERÊNCIAS}

ANTONIAZZI, Mariela Moralles. Mercosurización de la democracia y los derechos humanos. Disponível em: http://derecho. posgrado.unam.mx/congresos/antonazzi/MMAMercosurizacion02082014.pdf. Acesso em: 17 abr. 2017.

BRASIL. Protocolo de Assunção. Disponível em: http://www.planalto.gov.br/ccivil_03/_Ato2007-2010/2010/Decreto/D7225. htm. Acesso em: 25 abr. 2017.

BRASIL. Tratado de Assunção. Disponível em: http://www.stf.jus.br/arquivo/cms/processoAudienciaPublicaAdpf101/anexo/ Tratado_de_Assuncao.pdf. Acesso em 10 fev. 2017.

BRASIL. Ministério das Relações Exteriores. Integração Latino-Americana: 50 anos da Alalc/Aladi. Brasília: Fundação Alexandre Gusmão, 2010.

BRASIL. Ministério das Relações Exteriores. Mercosul. Disponível em: http://www.itamaraty.gov.br/pt-BR/politica-externa/integracao-regional/686-mercosul. Acesso em: 25 mar. 2019.

CEPAL. Comissão Econômica para América Latina e Caribe. Disponível em: http://www.cepal.org/pt-br. Acesso em: 15 mar. 2017.

CEPAL. O mercado comum latino-americano. In: BIELSCHOWSKY, Ricardo (org.). Cinqüenta anos de pensamento na Cepal. Rio de Janeiro: Record, 2000. Disponível em: http://archivo.cepal.org/pdfs/cdPrebisch/123.pdf. Acesso em: 3 mar. 2017.

CANDAU, Vera Maria. Direitos humanos, educação e interculturalidade: as tensões entre igualdade e diferença. Revista Brasileira de Educação, v. 13, n. 37, jan./abr. 2008.

CEPAL. Comissão Econômica para a América Latina e o Caribe. O mercado comum latino-americano. In: BIELSCHOWSKY, Ricardo (org.). Cinqüenta anos de pensamento na Cepal. Rio de Janeiro: Record, 2000. Disponível em: https://www.cepal.org/sites/ default/files/publication/files/1607/S33098N962Av2_pt.pdf. Acesso em: 3 mar. 2017. 
CMC. Conselho do Mercado Comum. Gestor de documentos. Disponível em: https://gestorweb.mercosur.int/?pag=n\&tab=0\&lang=pt. Acesso em: 5 abr. 2017.

COELHO, Maria Francisca Pinheiro; TAPAJÓS, Maria de Souza; RODRIGUES, Monica (org.). Políticas sociais para o desenvolvimento: superar a pobreza e promover a inclusão. Simpósio Internacional sobre Desenvolvimento Social. Brasília: Ministério do Desenvolvimento Social e Combate à Fome; Unesco, 2010.

DUGUIT, Rui. Fundamentos do Direito. São Paulo: Martin Claret, 2009.

EL PAÍS INTERNACIONAL. Mercosul pressiona Venezuela com a cláusula democrática. Disponível em: http://brasil.elpais.com/ brasil/2017/04/01/internacional/1491076022_326137.html. Acesso em: 10 jun. 2017.

FLORES, Joaquín Herrera. A reinvenção dos direitos humanos. Entrevista concedida a José Geraldo de Souza Júnior para Constituição \& Democracia - Observatório da Constituição e da Democracia; Sindijus, Brasília: UnB, n. 23, jun. 2008.

GOMES, Eduardo Biacchi. Blocos econômicos: solução de controvérsias. 3. ed. Curitiba: Juruá, 2010.

GOMES, Eduardo Biacchi. Democracia e o Parlamento do Mercosul - rumos da integração sul-americana. Revista do Senado, Brasília, a. 48, n. 191, jul./set. 2011. Disponível em: https://www2.senado.leg.br/bdsf/bitstream/handle/id/242908/000926848. pdf?sequence=1. Acesso em: 23 mar. 2017.

GOMES, Eduardo Biacchi. Manual de Direito da Integração Regional. 1. ed. Curitiba: Juruá, 2012.

IPPDH. Instituto de Políticas Públicas em Direitos Humanos do Mercosul. Disponível em http://www.ippdh.mercosur.int/pt-br/ funciones-pt. Acesso em: 4 jul. 2016.

ISM. Instituto Social do Mercosul. Disponível em: http://ismercosur.org/Mercosul-social/?lang=pt-br. Acesso em: 1 jun. 2017. KROLING, Aloísio; MARTINS, Marianne Rios de Souza. O Papel da Políticas Públicas na Efetividade dos Direitos Humanos Fundamentais de 2a Dimensão. Revista Depoimentos, n. 10, p. 144-170, jan./dez. 2006. Disponível em: http://docplayer.com.br/ 5038623-Faculdade-de-direito-de-vitoria-fdv-depoimentos.html. Acesso em: 1a abr. 2020.

MARTINS, Eliane M. Octaviano. Sistemática de Solução de Controvérsias do Mercosul: o Protocolo de Brasília. Cadernos PROLAM/USP, ano 5, v. 1, p. 79-93, 2006. Disponível em: http://www.unisantos.br/upload/menu3niveis_1265908234981_eliane_ maria_octaviano_martins_sistematica_de_solucao_de_controversias_do_mercosul.pdf. Acesso em: 27 maio 2017.

MAZZUOLI, Valério de Oliveira. Curso de direito internacional público. 9. ed. rev., atual e ampl. São Paulo: Editora Revista dos Tribunais, 2015.

MAZZUOLI, Valério de Oliveira. Curso de direitos humanos. Rio de Janeiro: Forense; São Paulo: Método, 2014.

MELLO, Celso D. de Albuquerque. Direito Internacional da Integração. Rio de Janeiro: Renovar, 1996.

MELLO, Celso D. de Albuquerque. Direito Internacional Econômico. Rio de Janeiro: Renovar, 1993.

MERCOSUL. Disponível em: http://www.mercosul.gov.br. Acesso em: 5. jan. 2021.

MERCOSUR. Protocolo de Ouro Preto. 1994. Disponível em: http://www.mercosur.int/msweb/SM/Normas/PT/CMC_1994_OuroPreto.pdf. Acesso em: 10 jan. 2017.

MERCOSUR. Protocolo de Ushuaia. 1998. Disponível em: http://www.mercosur.int/innovaportal/file/110/1/1998_protocolo_ de_ushuaia-compromiso_democratico_port.pdf. Acesso em: 17 maio 2017.

MORAES, Filomeno; FORTES, Gabriel Barroso Democracia na América Latina: o Protocolo de Ushuaia e as relações institucionais no Mercosul. Disponível em: http://www.publicadireito.com.br/artigos/?cod=1a3650aedfdd3a21. Acesso em: 10 jun. 2017.

PARLASUL. Parlamento do Mercosul. Disponível em: https://www.parlamentomercosur.org. Acesso em: 31 mar. 2017.

PATRINÓS, Paula Rodriguez. Institucionalidad pública para la protección y promoción de los Derechos Humanos en el Mercosur. In: SARTI, Ingrid (org.). Os desafios da integração sul-americana: autonomia e desenvolvimento. Rio de Janeiro: Letra e Imagem, 2014.

PIOVESAN, Flavia. Direitos humanos e globalização. In: SUNFELD, Carlos Ari (coord.). Direito global. São Paulo: Malheiros, 1999. PIOVESAN, Flavia. Direitos humanos e o direito constitucional internacional. 12. ed. rev. e atual. São Paulo: Saraiva, 2011.

PIOVESAN, Flavia. Pobreza e desigualdade no Brasil: traçando caminhos para a inclusão social. In: WERTHEIN, Jorge (org.). Brasília: Unesco, 2003. Disponível em: http://unesdoc.unesco.org/images/0013/001339/133974por.pdf. Acesso em: 23 jul. 2016.

PITANGUY, Jacqueline; HERINGER, Rosana. Direitos humanos no Mercosul. Cadernos Fórum Civil, ano 3, n. 4. Disponível em: http://www.cepia.org.br/doc/livro4forum.pdf. Acesso em: 1‥ fev. 2017.

RAADH. Reunião das Altas Autoridades em Direitos Humanos. Iniciativas regionais de direitos humanos são ampliadas. Disponível em: http://www.raadh.mercosur.int/pt-br/iniciativas-regionais-de-direitos-humanos-sao-ampliadas/. Acesso em: 4 jul. 2016.

RIBEIRO, Daniela Menegoti; DOS ANJOS, Luiz Sérgio Moreira. Desenvolvimento, políticas púbicas e direitos humanos: o acordo multilateral de seguridade social do MECOSUL. Revista de Direito Brasileira, v. 2011. Disponível em: http://www.rdb.org.br/ ojs/index.php/rdb/article/viewFile/61/60. Acesso em: 1o maio 2020. 
ROSEVICS, Larissa. Por uma integração via educação: o novo marco do Mercosul Educacional no século XXI. Revista Neiba. v. IV, n. 1 ago. 2015. Disponível em: www.e-publicacoes.uerj.br/index.php/neiba/article/download/13807/13523. Acesso em: 27 maio 2017.

SACHS, Ignacy. Desenvolvimento, direitos humanos e cidadania. In: PINHEIRO, P. S.; GUIMARÃES, S. P. (org.). Direitos humanos no século XXI. [S.I.]: Instituto de Pesquisa de Relações Internacionais e Fundação Alexandre de Gusmão, 1998.

SEVERINO, Antônio Joaquim. Metodologia do trabalho científico. 23. ed. rev. e atual. São Paulo: Cortez, 2007.

SOUZA JÚNIOR, José Geraldo; ESCRIVÃO FILHO, Antônio. Para um debate teórico-conceitual e político sobre os Direitos Humanos. Belo Horizonte: Editora D'Plácido, 2016.

SOUZA JÚNIOR, José Geraldo; ESCRIVÃO FILHO, Antônio. Discurso social e cidadania: movimento social e práticas instituinte de direito (ética e direitos humanos). In: Revista Ethos. Brasília: Sociedade de Estudos e Pesquisas éticas de Brasília - Sepeb, 2000. p. 171-190. p. 183.

STF. Supremo Tribunal Federal. Internacional. Novos rumos para o Instituto Social do Mercosul (ISM). Disponível em: http:// www2.stf.jus.br/portalStfInternacional/cms/destaquesNewsletter.php?sigla=newsletterPortallnternacionalNoticias\&idConteudo=308053. Acesso em: 4 jun. 2017.

TEIXEIRA, José Horácio Meirelles. Curso de Direito Constitucional. Rio de Janeiro: Forense, 1991.

VARELLA, Marcelo D. Direito internacional público. 4. ed. São Paulo: Saraiva, 2012.

WINTER, Luís Alexandre Carta. O Mercosul e o sistema presidencialista. 2008. Tese (Doutorado) - Prolam-USP, São Paulo, 2008. Disponível em: http://www.teses.usp.br/teses/disponiveis/84/84131/tde-10112009-144912/pt-br.php. Acesso em: 2 dez. 2016.

WINTER, Luís Alexandre Carta; BECKERS, Amanda Carolina. Desenvolvimento e integração regional: a atuação do Mercosul em políticas públicas de direitos humanos. In: Revista Direitos Humanos em Perspectiva, v. 2, n. 2, 2016. Disponível em: http:// www.indexlaw.org/index.php/direitoshumanos/article/view/1398. 